2

3

\title{
Effect of a single point mutation on the interaction of glucans with a glucansucrase from
}

Leuconostoc mesenteroides NRRL B-1118

Gregory L. Côté* and Christopher D. Skory

Renewable Product Technology Research Unit

National Center for Agricultural Utilization Research

Agricultural Research Service

United States Department of Agriculture

1815 North University Street

Peoria, Illinois 61604 USA

\section{*greg.cote@ars.usda.gov}

Keywords: dextran, dextransucrase, glucansucrase, glucosyltransferase, glucan-binding domain 


\begin{abstract}
Our previous work showed that substitution of an amino acid that is coupled with the +2 subsite adjacent to the transition stabilizer of a glucansucrase, which produces a water-insoluble glucan, resulted in significant changes in the structures and yields of the water-insoluble glucans produced. We now describe how these changes affect the ability of the glucansucrase to bind to exogenous glucans, and how these glucans can influence the yield, product structures, and kinetics of the mutant glucansucrases. The activity of the wild-type enzyme, with threonine at position 654 , is not significantly activated by added dextran, and the yield of water-insoluble glucan from sucrose is only slightly increased by dextran. Mutant T654Y is not affected at all by the addition of dextran. However, several mutant enzymes exhibit markedly lower yields of glucan relative to the wild type; these lower yields can be partially or completely overcome by the addition of water-soluble dextran. Although evidence indicates that the soluble dextran is incorporated into water-insoluble glucan, the increased yields cannot be accounted for solely by incorporation of the dextran into insoluble product. Furthermore, these DsrI mutants are significantly activated by exogenous glucans. The addition of dextran does not markedly change the $K_{M}$ for sucrose in the mutant enzymes, but does increase the $V_{\max }$ of the reaction. These effects apparently depend on the presence of unbranched sequences of $\alpha 1 \rightarrow 6$-linked D-glucose units in the glucan.

\section{Introduction}

Leuconostoc mesenteroides strain NRRL B-1118 produces at least two extracellular glucosyltransferases: a dextransucrase (DsrS, EC 2.4.1.5), which produces a water-soluble dextran linked predominantly $\alpha 1 \rightarrow 6$, and a glucansucrase (DsrI, EC 2.4.1.125), which produces a water-insoluble glucan with both $\alpha 1 \rightarrow 6$-linked domains and $\alpha 1 \rightarrow 3$-linked domains. ${ }^{1}$ We have previously cloned and expressed these enzymes in Escherichia coli ${ }^{1}$ as well as in Lactococcus lactis, ${ }^{2}$ and demonstrated that certain mutations at threonine 654 in the latter enzyme, DsrI, significantly affect the yields and structures of the insoluble glucans produced. In particular, mutants T654I, T654K, T654R, T654Q and T654N produced insoluble glucans with higher percentages of $\alpha 1 \rightarrow 3$ linkages, albeit in much lower yields. ${ }^{3}$ Furthermore, these same DsrI mutants had increased activity in the presence of soluble dextran, while the native DsrI and most of the other mutant enzymes were unaffected. Similar activation by dextran has been described with numerous glucansucrases from Streptococcus and L. mesenteroides that include enzymes producing both soluble and insoluble glucan. ${ }^{4-11}$ The mechanism of this activation is currently unknown, but many early theories originally postulated that dextran served as primer during the glucosyl transfer from sucrose to the growing glucan chain. The glucan binding domain for this dextran-stimulated transfer is critical as demonstrated by the complete loss of activation when the C-terminal glucan binding domain was removed from the $S$. sobrinus GTF-I (glucosyltransferase, insoluble-glucan-producing). ${ }^{7}$ In addition, replacing the glucan binding
\end{abstract}


domain of the primer-independent S. mutans GTF-I with that from the primer-dependant GTF-S

2 (soluble glucan-producing) resulted in hybrids that were stimulated by dextran. ${ }^{12}$

Activation cannot be full explained by the primer model, since dextran treated with tripsyl chloride, which blocks the nonreducing ends of dextran and prevents further extension by glucansucrase, still activated GTF-I from S. mutans. ${ }^{13}$ It has been suggested that dextran activation is an allosteric effect or that dextran binding alters the catalytic site. ${ }^{8,13}$ However, one should not discount that dextran can also serve as an acceptor for the glucosyl transfer. ${ }^{6,8,14,15}$ The modified DsrI from L. mesenteroides provide a unique example to study this dextran activation since the full-length enzymes differing by only one amino acid have significant differences with this so-called "primer effect". We now follow up on that work with experiments designed to investigate the underlying mechanism behind those findings, and to exploit those results with methods for the production of modified glucan structures in increased yields.

\section{Experimental}

Enzymes

Glucansucrases genes were cloned as previously described ${ }^{1,3}$ and expressed in Lactococcus lactis. $^{2}$ The L. lactis cultures were centrifuged to remove cells, and the cell-free culture fluid was concentrated and diafiltered against $20 \mathrm{mM}$ sodium acetate buffer ( $\mathrm{pH} 5.6)$ containing $2 \mathrm{mM}$ $\mathrm{CaCl}_{2}$ and $1.5 \mathrm{mM} \mathrm{NaN}_{3}$, using a tangential-flow apparatus with a 100,000 MW cutoff membrane cassette (Millipore, Billerica, MA, USA). The concentrated and diafiltered culture fluid was used without further purification.

Endodextranase (Dextranase L) from Chaetomium sp. was a gift from Amano Enzymes USA (Elgin, IL), and contained approximately 30,000 U/mL.

\section{Carbohydrates}

${ }^{14} \mathrm{C}-\mathrm{U}-\mathrm{S}$ crose was purchased from MP Biochemicals, LLC (Santa Ana, CA). Industrial-grade dextrans of various molecular weight ranges were purchased from Sigma-Aldrich, USA. Native, high-Mw NRRL B-1355, B-1498, B-1501, and B-21297 alternan was prepared as previously described. ${ }^{16,17}$ Alternan modified by endodextranase treatment was prepared as described by Leathers et al., ${ }^{18}$ and NRRL B-742 and B-1355-L dextran fractions were prepared as previously described. ${ }^{19-21}$ Their respective molecular weights were as follows: Native high-Mw glucans were approximately $10^{7}$; alternan modified by endodextranase was bimodal, at $5 \times 10^{6}$ and $4 \times 10^{5}$; and endodextranase-treated B-742-S was $5 \times 10^{3}$. All were readily soluble in water at the concentrations used. All other carbohydrates were reagent grade. 
DsrS (soluble-dextran producing dextransucrase) from L. mesenteroides NRRL B-1118 was cloned and expressed in E. coli as previously described. ${ }^{22}$ This was used to synthesize ${ }^{14} \mathrm{C}$ labeled B-1118 soluble dextran. One $\mathrm{mL}$ of DsrS containing $0.67 \mathrm{U} / \mathrm{mL}$ was mixed with $0.4 \mathrm{~mL}$ of $0.3 \mathrm{M}{ }^{14} \mathrm{C}$-U-sucrose $\left(42 \mathrm{cpm} / \mu \mathrm{g}\right.$ ) in $20 \mathrm{mM}$ sodium acetate buffer, $\mathrm{pH} 5.5$, with $2 \mathrm{mM} \mathrm{CaCl}_{2}$ and $1.5 \mathrm{mM} \mathrm{NaN}_{3}$. After the reaction was complete, the reaction mixture was mixed with 1.5 volumes of ethanol, and the precipitate was collected by centrifugation. This was redissolved in 3 $\mathrm{mL}$ of water and precipitated a second time with ethanol. A total of three dissolutionreprecipitation steps were performed to remove all low-Mw ${ }^{14} \mathrm{C}$ sugars. The ${ }^{14} \mathrm{C}$-labeled watersoluble dextran $(42 \mathrm{cpm} / \mu \mathrm{g})$ was dissolved in buffer $(14.5 \mathrm{mg} / \mathrm{mL})$. Equal volumes of ${ }^{14} \mathrm{C}$ dextran solution, $1 \mathrm{M}$ sucrose, and DsrI mutant T654R enzyme $(0.9 \mathrm{U} / \mathrm{mL})$ were allowed to incubate at room temperature with mixing by gentle rocking. After 2.5 days, the mixture was centrifuged and the water-insoluble glucan product was separated from the soluble reaction products. The insoluble material was washed with water three times, followed by one wash in $50 \%$ ethanol and one wash in absolute alcohol, then dried in vacuo at $50^{\circ} \mathrm{C}$. The dried waterinsoluble material and the soluble supernatant solution were both analyzed for ${ }^{14} \mathrm{C}$ content by liquid scintillation counting in Ecolume cocktails.

\section{Analytical methods}

Glucansucrase radioassays, NMR, dextranase susceptibility studies and thin-layer chromatography techniques have been described. ${ }^{1,3}$

\section{Results}

\section{Activation by soluble glucans}

In our previous work, we showed that several DsrI mutants expressed in E. coli were activated by water-soluble dextran $(2,000,000 \mathrm{Mw}) .{ }^{3}$ We have now determined the kinetic constants $\mathrm{K}_{\mathrm{M}}$ and $\mathrm{V}_{\max }$ for those mutants of DsrI expressed and secreted extracellularly in Lactococcus lactis. Using a constant concentration of $0.83 \%(\mathrm{w} / \mathrm{v})$ dextran and varying sucrose concentrations in the range of $7.5 \mathrm{mM}$ to $150 \mathrm{mM}$, Eadie-Hofstee plots were constructed, and $\mathrm{K}_{\mathrm{M}}$ values for sucrose were calculated. $\mathrm{V}_{\max }$ values were also calculated, but since these are dependent on enzyme concentrations present in the reaction mixtures, we present in Table 1 the $\mathrm{V}_{\max }$ in the presence of dextran relative to $\mathrm{V}_{\max }$ in the absence of dextran, as the ratio $\mathrm{V}_{\max }+/ \mathrm{V}_{\max }-$. One-way ANOVA (Analysis of Variance) was performed (t-tests) to determine the significance of any differences in $\mathrm{K}_{\mathrm{M}}$ and $\mathrm{V}_{\max }$ values. In all cases tested, the absence or presence of dextran did not significantly alter the $K_{M}$ for sucrose with any DsrI mutant. However, the $V_{\max }$ was significantly increased by the addition of dextran for T654 mutants K, I, R, N, and Q, whereas it was essentially unchanged for the wild type and mutant T654Y.

Several glucans other than commercial dextran were also analyzed for their ability to activate the mutant enzymes. Soluble starch, levan and pullulan showed no effect, but native, high Mw 
1 alternan from several sources (NRRL B-1355, B-1498, B-1501, and B-21297) caused significant 2 activation of T654K, I, R, N and Q. Similarly, native dextran fraction NRRL B-742-S ${ }^{19,20}$ also

3 activated these DsrI mutants. None of these glucans caused significant activation of the wild-type 4 enzyme, nor of mutant T654Y. However, alternan modified by treatment with endodextranase ${ }^{18}$ 5 showed no activation of any of the mutant enzymes, nor did endodextranase-limit B-742-S $6 \operatorname{dextran}^{20,21}$ (data not shown).

\section{Increase in insoluble glucan yield}

Yields of water-insoluble glucan were measured for all of the mutant enzymes mentioned above with 2,000,000 Mw dextran (Figure 1), and for mutant T654R with dextran fractions of 2,000,000 Mw, 200,000 Mw, and 20,000 Mw (Figure 2). Mutant T654R was selected for most of the yield enhancement studies because its yield was the most affected by dextran (Fig. 1). The yield of water-insoluble glucan from T654Y, already the highest in the absence of dextran, was not increased by addition of dextran. Yield from the wild-type was initially increased a small amount by dextran, but quickly reached a maximum. Mutant enzymes T654K, I, R, N and Q were all significantly affected by added dextran. In the absence of dextran, they each produced much less insoluble glucan than the wild type. However, soluble dextran was able to increase the yields to levels equal to or higher than either the wild type or T654Y.

In Figure 2, it is evident that the molecular weight of the added dextran must play a role in the yield of water-insoluble glucan formed, at least by mutant DsrI T654R. The highest Mw dextran tested, 2,000,000, increased the yield of water-insoluble product throughout the range tested. Higher concentrations could not be tested because the resulting reaction mixture was a semisolid gel. The lowest $\mathrm{Mw}$ dextran tested, 20,000, initially increased insoluble yields to the same level as high-Mw dextran, but yields decreased slightly at higher concentrations. The intermediate $\mathrm{Mw}$ range dextran, 200,000, resulted in a yield curve intermediate to the other two.

In addition to commercial dextran fractions, the fraction $\mathrm{L}$ dextran produced by Leuconostoc citreum NRRL B- $1355^{19}$ was also capable of increasing yields of insoluble glucan when tested with mutant T654R, as were native, high-Mw alternan fraction from L. citreum NRRL B-1501 and B-21297 (Fig. 3), although in none of these cases was the increase as great as it was with high-Mw $(2,000,000)$ B-512F commercial dextran. Soluble starch or dextranase-treated alternan did not increase the yields of insoluble glucan formed by T654R.

\section{Structures of insoluble products}

In the case of T654R with added 2,000,000 Mw dextran, the resistance of the water-insoluble glucan to dextranase hydrolysis was $80 \%$ when synthesized in the absence of dextran, and decreased to $38 \%$ at the maximum amount of dextran added (Fig. 4). This indicates an increase 
in the proportion of dextranase-susceptible $\alpha(1 \rightarrow 6)$-linked glucan linkages in the insoluble product. Again using the example of insoluble glucan formed by T654R in the presence and absence of 2,000,000 Mw dextran, NMR analysis showed a large increase in the proportion of $\alpha(1 \rightarrow 6)$-linkages when water-soluble dextran was present during the synthesis. As illustrated by Figure 5, the peak at $\sim 97 \mathrm{ppM}$, which arises from anomeric carbon in $\alpha(1 \rightarrow 6)$-linkage, is much larger than the peak at $\sim 102 \mathrm{ppM}$, which arises from an anomeric carbon in $\alpha(1 \rightarrow 3)$-linkage, when the insoluble glucan is formed in the presence of dextran. Likewise, peaks at $\sim 61$ and $\sim 66$ ppM, which arise from unlinked and linked C-6, respectively, reflect the same change.

\section{${ }^{14}$ C Labeling experiment}

11 Duplicate experiments were carried out with ${ }^{14} \mathrm{C}$-labeled dextran, as described in the 12 Experimental section. After liquid scintillation counting of the ${ }^{14} \mathrm{C}$ present in the soluble and 13 insoluble phases after reaction with DsrI from T654R, it was found that $>99 \%$ of the ${ }^{14} \mathrm{C}$ soluble phase. No significant incorporation was measured with the wild-type enzyme.

\section{Discussion}

Two related phenomena have been demonstrated by this work. Firstly, we have shown that specific point mutations at threonine 654 of the cloned B-1118 DsrI are capable of altering the enzyme from one that is not activated by dextran to one that is activated by dextran. In these cases, activation is a result of changes in the $V_{\max }$ of the enzyme, with no alteration in the $K_{M}$ for sucrose. This is in similar to glucosyltransferases GtfK (primer stimulated), GtfL (primer independent), and GtfM (primer independent) from $S$. salivarius, where there was no change to the $\mathrm{K}_{\mathrm{M}}$ for sucrose in the presence of $\mathrm{T} 10$ dextran. ${ }^{9}$ However, dextransucrase from S. sanguis showed more than a ten-fold decrease in $\mathrm{K}_{\mathrm{M}}$ for sucrose in the presence of dextran T10. ${ }^{8}$ In addition, they found that $\mathrm{V}$ (normalized to $\mathrm{V}$ per unit of enzyme) was approximately two times higher in the presence of dextran. The results with DsrI implies that significant conformational changes probably do not occur at the sucrose binding site upon altering threonine 654. However, some changes must occur which enable an increase in initial reaction velocity upon binding to dextran.

Secondly, the increases in reaction rates are accompanied by increases in yields of waterinsoluble glucan. The fact that the resulting insoluble glucan contains an increased proportion of $\alpha(1 \rightarrow 6)$-linkages (Figs. 4 and 5) suggests that some of the added dextran may be incorporated into the water-insoluble product. When the ${ }^{14} \mathrm{C}$ labeling results are taken into account, it becomes clear that the added water-soluble dextran must be incorporated into the water-insoluble product, most likely via acceptor reactions. Graft copolymer has been postulated by others for streptococcal enzymes, ${ }^{23-30}$ and must also be occurring here. However, additional phenomena 
must also be accounted for. Firstly, the incorporation of dextran into water-insoluble product does not by itself explain the increase in initial rates of synthesis by dextran. Secondly, the incorporation of dextran into final insoluble product does not entirely explain the increases in yield. For example, the addition of $50 \mathrm{mg}$ of water-soluble dextran resulted in a $124 \mathrm{mg}$ increase in water-insoluble glucan synthesis by DsrI T654R (Figs. 1-3). Even if all of the dextran were incorporated into water-insoluble product, that leaves $74 \mathrm{mg}$ in increased yield unexplained.

To explain these results, one must bear in mind that, even though all of the sucrose is consumed in these experiments, in the absence of added dextran, not all of the glucosyl units from sucrose are incorporated into glucan. Instead, significant amounts are transferred to the fructose released from sucrose, in what are known as acceptor reactions, yielding the disaccharide leucrose. ${ }^{6}$ In the case of some mutants, such as T654I and T654K, these acceptor reactions account for the majority of glucosyl transfer reactions when dextran is absent. Apparently, the addition of dextran alters the rate of glucan synthesis and the proportion of glucosyl units going into glucan synthesis instead of acceptor reactions is also increased. Again, this suggests the possibility that dextran acts as both an allosteric activator and as an acceptor.

One possibility may involve the differences in acceptor binding (e.g., +1 and +2 subsites) between the T654 mutants. It has been proposed that the amino acids following the transition state stabilizer are involved in orientation of the acceptor molecule and influence the type of glycosidic bond that is formed. ${ }^{31,32}$ Therefore, it would be expected that any alterations within this region may also influence the affinity of acceptor binding and enzyme efficiency. As an example, activity increased with the degree of polymerization with glucansucrase from $S$. sobrinus ${ }^{6}$ and $S$. sanguis. ${ }^{8}$ We propose that T654 substitutions may result in either improved binding of dextran acceptor or decreased binding of fructose through steric interference. Alternatively, the results presented here can be interpreted as lending support to the types of mechanisms described by Komatsu et al. ${ }^{6}$ for insoluble glucan synthesis by Streptococcus sobrinus GtfI and by Leemhuis et al. ${ }^{32}$ for glucansucrases in general. In the latter model, there is flexibility in the position of the glucan-binding domain relative to the rest of the glucansucrase. ${ }^{33}$ The proximity and relative position of one to the other can influence the extent of polymer formation vs. oligomer formation. Although there is no direct evidence, it is possible that in some of our mutants, the change in threonine 654 has altered the conformation about this hinge region. In the wild type and mutant T654Y, the two domains may be positioned such that binding of dextran is not necessary for optimal synthesis of insoluble glucan. However, in mutants T654K, I, R, N and Q, the two domains may be separated sufficiently to result in oligosaccharide synthesis rather than polymer synthesis. Binding to dextran could bring the two domains back into proper alignment for increased polymer synthesis. In the latter cases, the resulting glucan is also more similar to wild-type product compared to the mutant products synthesized de novo without dextran. Affinity binding studies with different acceptor molecules, including dextran, may help determine the mechanisms for this enzyme activation, but this would likely require removing the glucan-binding domain in order to limit the measurements within the active site. In 
addition, three dimensional structural analyses may be used to elucidate whether altered conformations associated with the hinge region are involved.

It is notable that the glucan binding domain in this enzyme is apparently selective for uninterrupted sequences of $\alpha(1 \rightarrow 6)$-linkages, even though the enzyme is characterized by the synthesis of sequences of $\alpha(1 \rightarrow 3)$-linkages. Germaine et al. ${ }^{4}$ found that neither glycogen, amylose, inulin, nor isomaltose were sufficient for stimulation of the primer dependent $S$. mutans dextransucrase. Several observations bear this out. Firstly, our mutants and the wild type all exhibit similar binding to Sephadex (cross-linked dextran) ${ }^{2}$, demonstrating that they all have intact and functional glucan-binding domains. Secondly, native alternan and B-742-S dextran activate the enzyme and give increased yields, but upon treatment with dextranase to eliminate uninterrupted and unsubstituted $\alpha(1 \rightarrow 6)$-linked regions, ${ }^{18,20}$ activation and increased yields disappear. Shah et al. ${ }^{34}$ found that alternan was capable of binding to glucan-binding domains of several glucansucrases, and interpreted their results to indicate that these regions could bind a variety of linkage sequences. However, they did not study binding to the same glucans after treatment with endodextranase, so it is possible that the binding they observed was due to the small stretches of $\alpha(1 \rightarrow 6)$-linked regions known to be present in native alternan. ${ }^{18}$ The results described here complement those of Walker and Schuerch ${ }^{27}$, who found that the degree of stimulation of Streptococcus mutans GTF-I by dextrans was inversely proportional to the degree of branching, and concluded that unsubstituted $\alpha(1 \rightarrow 6)$-linked regions were responsible for the activation effect. They also found increases in yields upon addition of soluble dextrans, with differences in the molecular weight of the added dextran showing little or no effect.

In addition to lending support to current ideas regarding the mechanism of glucansucrases, ${ }^{32,35}$ this work also provides information that can be exploited for the enhanced production of customtailored water-insoluble glucans. The increased yields induced by the addition and incorporation of water-soluble dextran into water-insoluble products is in itself a valuable property. Furthermore, the properties of the products may differ, depending on which water-soluble glucan is used. For example, the products formed in the experiment summarized in Figure 2 differ in their solubility and dispersibility. We have reason to believe that the yields of water-insoluble glucan formed in the presence of 20,000 Mw dextran reach a maximum and then decrease because of differences in the relative proportions and chain lengths of $\alpha(1 \rightarrow 6)$-linked regions and $\alpha(1 \rightarrow 3)$-linked regions; the decrease in water-insoluble glucan appears to be accompanied by an increase in water-soluble glucan. This was suggested by our observation that the reaction medium seemed to increase in viscosity. These graft copolymers apparently comprise a wide range of molecular weights and/or linkage ratios. When the case of alternan copolymers is considered, the possibilities increase. Finally, in Figure 3, we show the formation of waterinsoluble graft copolymer with NRRL B-1355-L dextran. This dextran fraction is currently being investigated for its ability to prevent corrosion on steel. ${ }^{36}$ Formation of an insoluble graft copolymer could render it less likely to wash off steel surfaces. 
1 This study, by showing that a single amino acid residue can change the effect of added dextran 2 on both enzyme activity and yields, provides the first example of a native enzyme in which both 3 effects are induced by a single residue, and provides an excellent model system for further 4 studies on the molecular mechanism of a glucansucrase. 


\section{Acknowledgments}

We thank Suzanne Unser and Kristina Glenzinski for their many hours of technical assistance, Dr. Karl Vermillion for his expert advice and assistance pertaining to NMR spectroscopy, and Dr. Joseph Rich for his support and encouragement of our work. This work was supported and carried out by the U.S. Department of Agriculture. Mention of trade names or commercial products in this publication is solely for the purpose of providing specific information and does not imply recommendation or endorsement by the U.S. Department of Agriculture. USDA is an equal opportunity provider and employer.

\section{References}

1. Côté, G. L.; Skory, C. D. Appl. Microbiol. Biotechnol., 2012, 93, 2387-2394.

2. Skory, C. D.; Côté, G. L. Appl. Microbiol. Biotechnol., 2015, (in press, DOI 10.1007/s00253015-6854-0)

3. Côté, G. L.; Skory, C. D. Appl. Microbiol. Biotechnol., 2014, 98, 6651-6658.

4. Germaine, G. R.; Chludzinski, A. M.; Schachtele, C. F. J.Bacteriol., 1974, 120, 287-294.

5. Germaine, G. R.; Harlander, S. K.; Leung, W.-L. S.; Schachtele, C. F. Infect.Immun., 1977, 16, 637-48.

6. Komatsu, H.; Abe, Y.; Eguchi, K.; Matsuno, H.; Matsuoka, Y.; Sadakane, T.; Inoue, T.; Fukui, K.; Kodama, T. FEBS J., 2011, 278, 531-540.

7. Konishi, N.; Torii, Y.; Yamamoto, T.; Miyagi, A.; Ohta, H.; Fukui, K.; Hanamoto, S.; Matsuno, H.; Komatsu, H.; Kodama, T.; Katayama, E. J. Biochem., 1999, 126, 287-295.

8. Mayer, R. M.; Matthews, M. M.; Futerman, C. L.; Parnaik, V. K.; Jung, S. M. Arch. Biochem. Biophys., 1981, 208, 278-287.

9. Simpson, C. L.; Cheetham, N. W. H.; Giffard, P. M.; Jacques, N. A. Microbiol., 1995, 141, 1451-1460.

10. Stringer, C. S.; Tsuchiya, H. M. J. Am. Chem. Soc., 1958, 80, 6620-6625. 
11. Tsuchiya, H. M.; Hellman, N. N.; Koepsell, H. J.; Corman, J.; Stringer, C. S.; Rogovin, S. P.; Bogard, M. O.; Bryant, G.; Feger, V. H.; Hoffman, C. A.; Senti, F. R.; Jackson, R. W. J. Am. Chem. Soc., 1955, 77, 2412-2419.

12. Nakano, Y. J.; Kuramitsu, H. K. J. Bacteriol., 1992, 174, 5639-5646.

13. Robyt, J. F.; Corrigan, A. J. Arch. Biochem. Biophys., 1977, 183, 726-731.

14. Mukasa, H.; Shimamura, A.; Tsumori, H. Infect. Immun., 1979, 23, 564-570.

15. Robyt, J. F.; Yoon, S. H.; Mukerjea, R. Carbohydr. Res., 2008, 343, 3039-3048.

16. Côté, G. L. Carbohydr. Poly., 1992, 19, 249-252.

17. Côté, G. L. Chapter 13 in Biopolymers, Vol. 5. A. Steinbüchel, Ed. Wiley-VCH, Weinheim, Germany. 2002. Pp. 323-350.

18. Leathers, T. D.; Nunnally, M. S.; Côté, G. L. Biotechnol. Lett. 2009, 31, 289-293.

19. Wilham, C. A.; Alexander, B. H.; Jeanes, A. Arch. Biochem. Biophys., 1955, 69, 61-75.

20. Côté, G. L.; Robyt, J. F. Carbohydr. Res., 1983, 119, 141-156.

21. Côté, G. L.; Leathers, T. D.; Ahlgren, J. A.; Wyckoff, H. A.; Hayman, G. T.; and Biely, P. Chapter 8. In: Chemistry of Novel Foods, Okai, H., Mills, O., Spanier, A. M., and Tamura, M., (eds.), ACS Symposium Series, 1997.pp. 95-109.

22. Côté, G. L.; Skory, C.D. In Green Polymer Chemistry: Biobased Materials and Biocatalysis III; Cheng, H.N., Gross, R. A., Smith. P.B., Eds.; ACS Symposium Series 1191; American Chemical Society: Washington, DC, 2015; Chapter 7.

23. Hare, M. D.; Svensson, S.; Walker, G. J. Carbohydr. Res., 1978, 66, 245-264.

24. Fukui, K.; Moriyama, T.; Miyake, Y.; Mizutani, K.; Tanaka, O. Infect Immun., 1982, 1-9.

25. Koga, T.; Sato, S.; Inoue, M.; Takeuchi, K.; Furuta, T.; Hamada, S. J.Gen.Microbiol., 1983, 129,751-754.

26. Hanada, N.; Takehara, T.; Itoh, M.; Saeki, E. FEMS Microbiol. Lett., 1986, 36, 173-175.

27. Walker, G. J.; Schuerch, C. Carbohydr. Res., 1986, 146, 259-270. 
1 28. Takehara, T.; Ansai, T.; Yamashita, Y.; Itoh-Andoh, M.; Hanada, N.; Kunimori, A. Oral Microbiol. Immunol., 1992, 7, 155-158.

29. Robyt, J. F.; Martin, P. J. Carbohydr. Res., 1983, 113, 301-315.

30. Mukasa, H.; Tsumori, H.; Shimamura, A. Carbohydr. Res., 2001, 333, 19-26.

31. Leemhuis, H.; Pijning, T.; Dobruchowska, J. M.; Dijkstra, B. W.; Dijkhuizen, L. Biocatal. Biotransform., 2012, 30,366-376.

32. Leemhuis, H.; Pijning, T.; Dobruchowska, J. M.; van Leeuwen, S. S.; Kralj, S.; Dijkstra, B. W.; Dijkhuizen, L. J. Biotechnol., 2013, 163, 250-272.

33. Pijning, T.; Vujičić-Žagar, A.; Kralj, S.; Dijkhuizen, L.; Dijkstra, B. W. FEBS J., 2014, 281, 2159-2171.

34. Shah, D. S. H.; Joucla, G.; Remaud-Simeon, M.; Russell, R. R. B. J. Bacteriol., 2004, 186, 8301-8308.

35. Moulis, C.; Joucla, G.; Harrison, D.; Fabre, E.; Potocki-Veronese, G.; Monsan, P.; RemaudSimeon, M. J. Biol. Chem., 2006, 281, 31254-31267.

36. Finkenstadt, V. L.; Côté, G. L.; Willett, J. L. Biotechnol. Lett., 2011, 33,1093-1100. 
1

2 Table 1. Effect of dextran $(2,000,000 \mathrm{Mw})$ on kinetic parameters $\mathrm{K}_{\mathrm{M}}$ and $\mathrm{V}_{\max }$ for DsrI mutants

3 expressed in Lactococcus lactis.

\begin{tabular}{rlccc}
4 & DsrI mutant & $\begin{array}{c}\mathrm{K}_{\mathrm{M}} \text { without dextran } \\
5\end{array}$ & $\begin{array}{c}\mathrm{K}_{\mathrm{M}} \text { with } 0.8 \% \text { dextran } \\
(\mathrm{mM} \text { sucrose, } \pm \text { std. dev. })\end{array}$ & $\mathrm{V}_{\max +/ \mathrm{V}_{\text {max }^{-}}}$ \\
\cline { 2 - 5 } 7 & Wild type & $39 \pm 3.5$ & $33 \pm 3.5$ & 0.9 \\
8 & T654Y & $46 \pm 1.4$ & $46 \pm 16$ & 0.9 \\
9 & T654Q & $36 \pm 5.8$ & $38 \pm 9.2$ & $\mathbf{1 . 3 *}$ \\
10 & T654R & $43 \pm 12$ & $44 \pm 1.4$ & $\mathbf{1 . 5 *}$ \\
11 & T654N & $36 \pm 0.6$ & $46 \pm 14$ & $\mathbf{1 . 7}$ \\
12 & T654I & $46 \pm 8.5$ & $46 \pm 13$ & $\mathbf{2 . 1 *}$ \\
13 & T654K & $27 \pm 7.6$ & $34 \pm 0.8$ & $\mathbf{3 . 4 *}$ \\
\hline
\end{tabular}

$14 *$ These values represent statistically significant increases in $\mathrm{V}_{\max }$ with added dextran.

15 


\section{Figure legends.}

2 Figure 1. Yields of water-insoluble glucan synthesized by various mutant forms of DsrI in the 3 presence of increasing amounts of water-soluble dextran ( $\mathrm{Mw}=2,000,000)$. Reactions consisted 4 of $2 \mathrm{~mL}$ of $1 \mathrm{M}$ sucrose, $2 \mathrm{~mL}$ of DsrI containing approximately $1-2 \mathrm{U} / \mathrm{mL}$, and $2 \mathrm{~mL}$ of dextran 5 of various concentrations, dissolved in $20 \mathrm{mM} \mathrm{pH} 5.5$ sodium acetate buffer with $2 \mathrm{mM} \mathrm{CaCl} 2$ 6 and $1.5 \mathrm{mM} \mathrm{NaN}_{3}$. All reactions were allowed to go to completion as judged by disappearance of 7 sucrose when analyzed by TLC. Top: Wild type and mutant T654Y. Bottom: Mutants T654I, K, $8 \mathrm{R}, \mathrm{N}$ and $\mathrm{Q}$.

9 Figure 2. Yields of water-insoluble glucan formed by DsrI mutant T654R in the presence of 10 various molecular weight fractions of dextran. T20=20,000 Mw; T200=200,000 Mw;

$11 \mathrm{~T} 2000=2,000,000 \mathrm{Mw}$. Reaction conditions same as in Fig. 1.

12 Figure 3. Yields of water-insoluble glucan formed by DsrI mutant T654R in the presence of 13 various water-soluble glucans. Conditions same as in Fig. 1.

14 Figure 4. Dextranase resistance of water-insoluble glucan produced by DsrI mutant T654R in 15 the presence of various amounts of 2,000,000 Mw dextran. Resistance is expressed as percent of 16 glucan remaining water-insoluble after exhaustive hydrolysis by endodextranase.

17 Figure 5. Proton-decoupled ${ }^{13} \mathrm{C}$-NMR spectra of water-insoluble glucans formed by DsrI mutant 18 T654R in the absence (top) and presence (bottom) of $0.83 \%$ (w/v) dextran, Mw=2,000,000. Peak 19 at $\sim 102 \mathrm{ppM}$ arises from anomeric carbon in $\alpha(1 \rightarrow 3)$-linkage, and peak at $\sim 97 \mathrm{ppM}$ from 20 anomeric carbon in $\alpha(1 \rightarrow 6)$-linkage. Likewise, peaks at $\sim 61$ and $\sim 66 \mathrm{ppM}$ arise from unlinked 21 and linked C-6, respectively. 

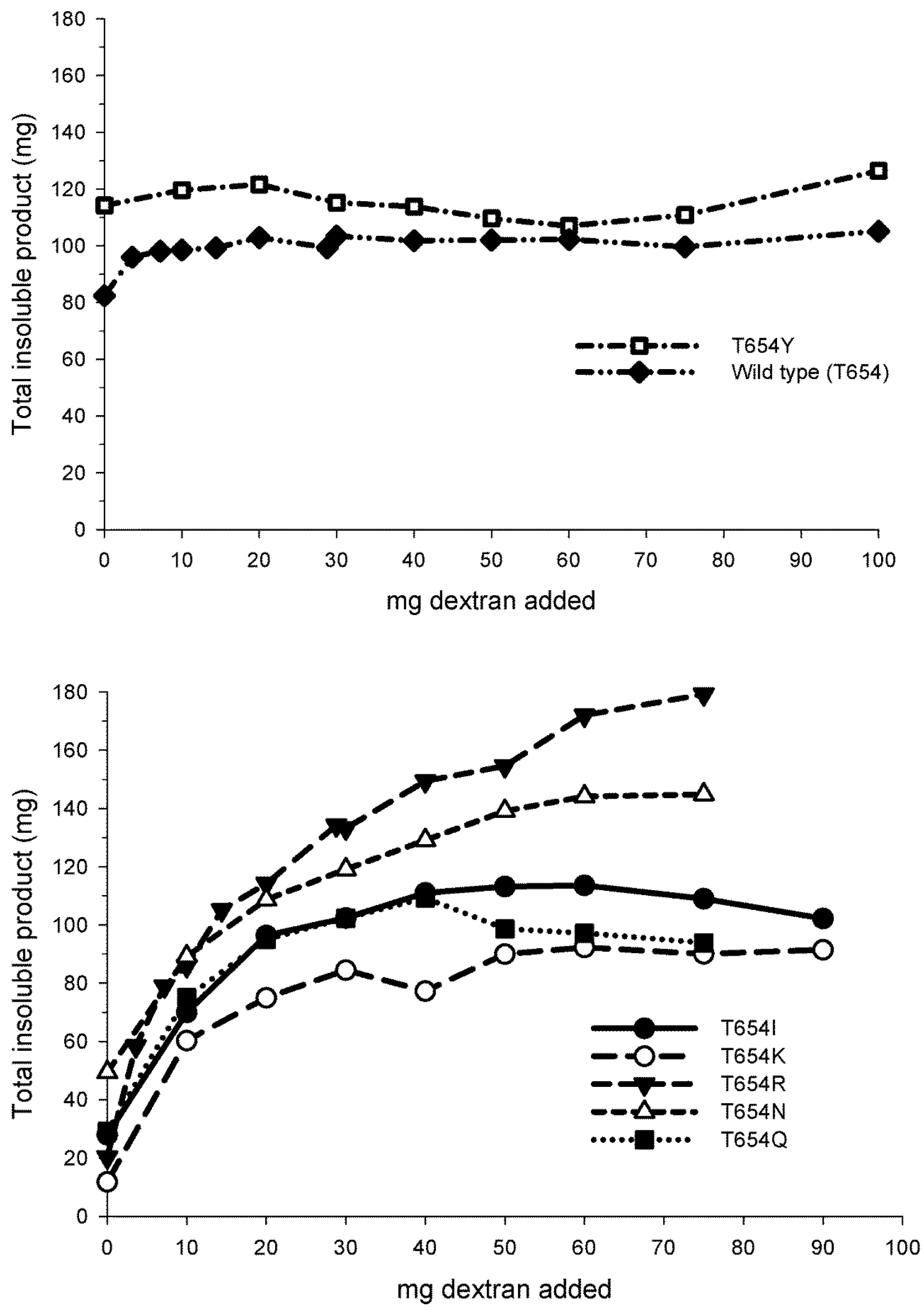

Figure 1. 


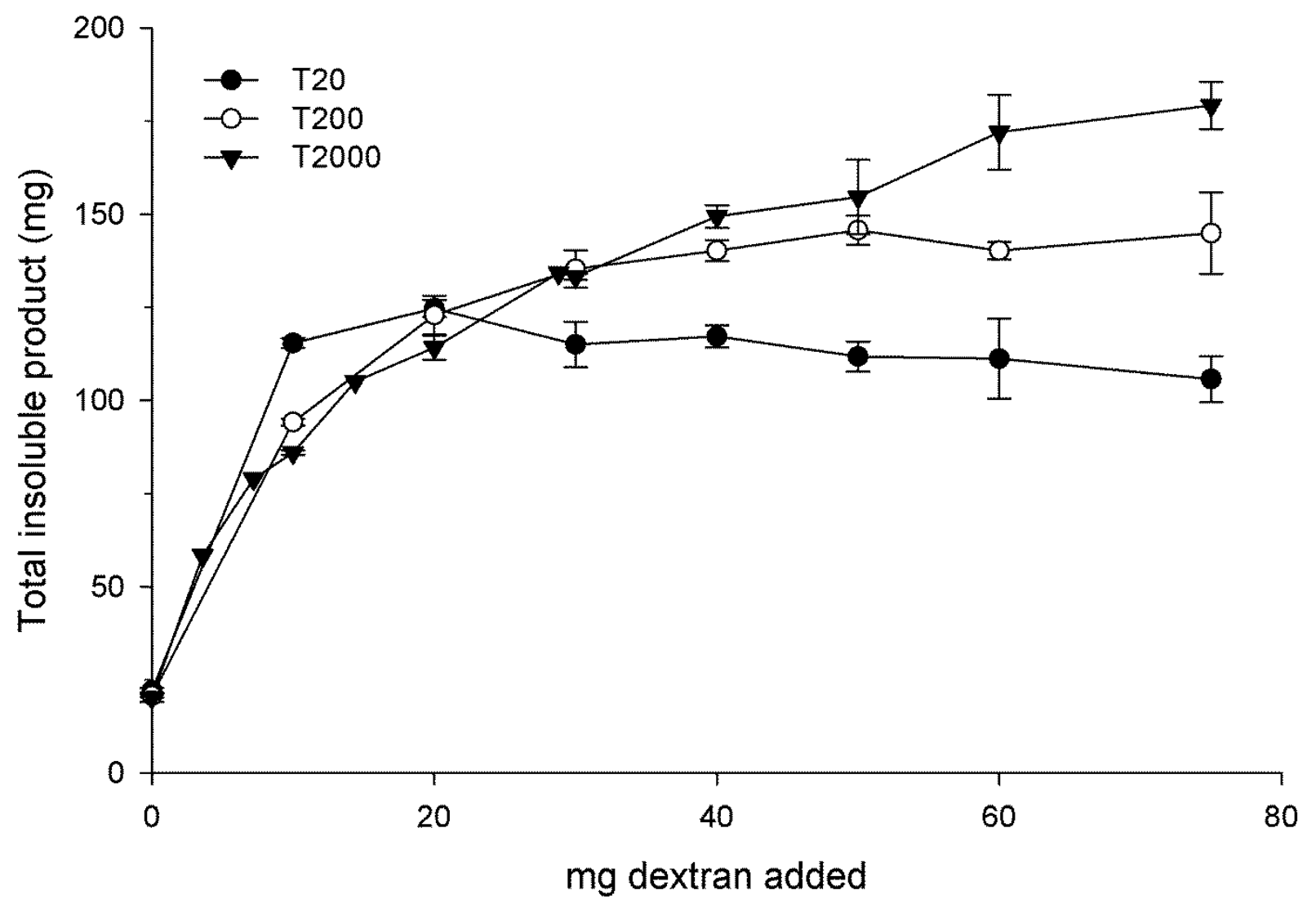

3 Figure 2.

39

40

41

42

43

44

45

46

47

48

49

50

51

52

53

54

55

56

57

58

59

60

61

62 


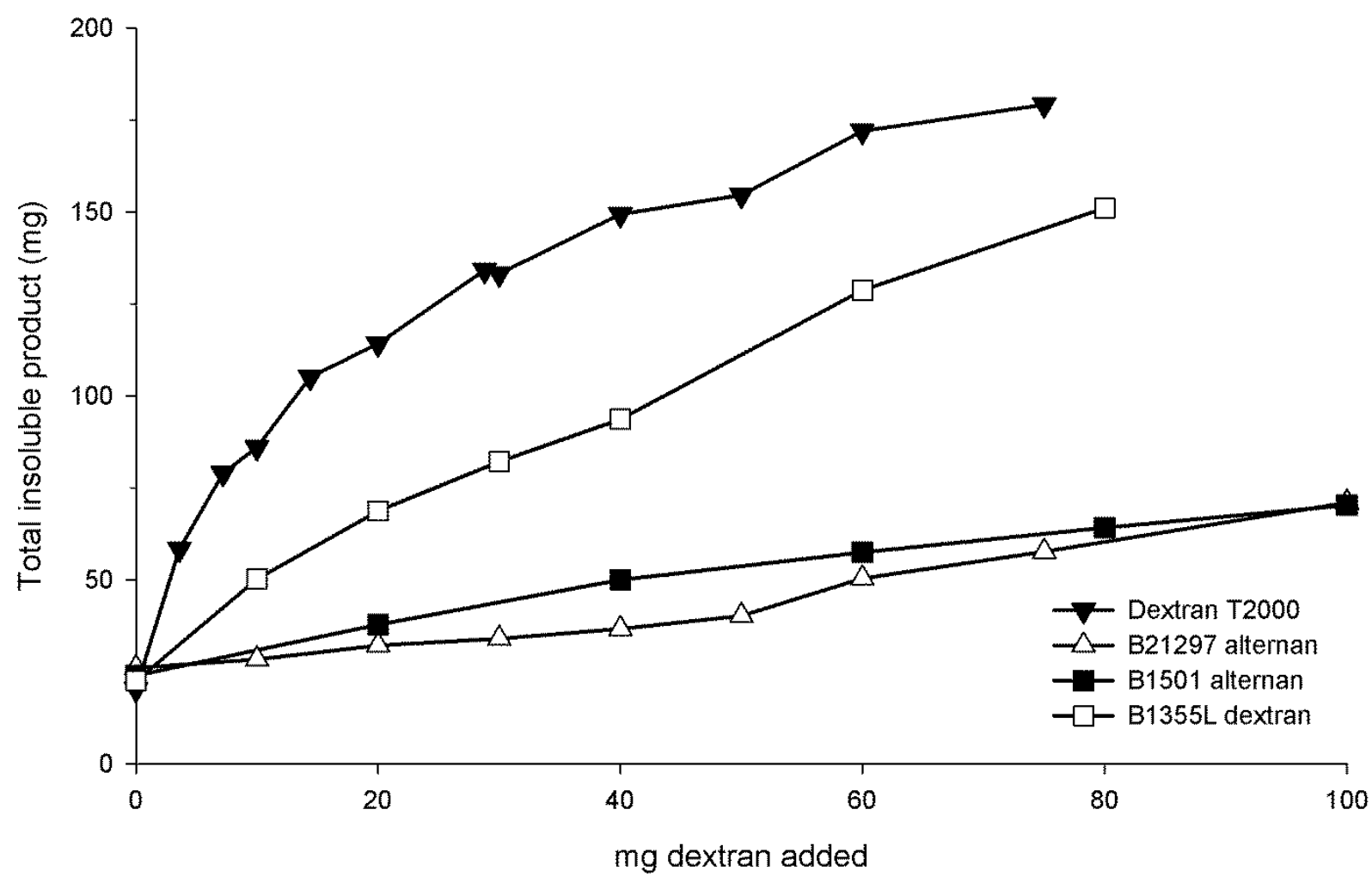

1

Figure 3. 


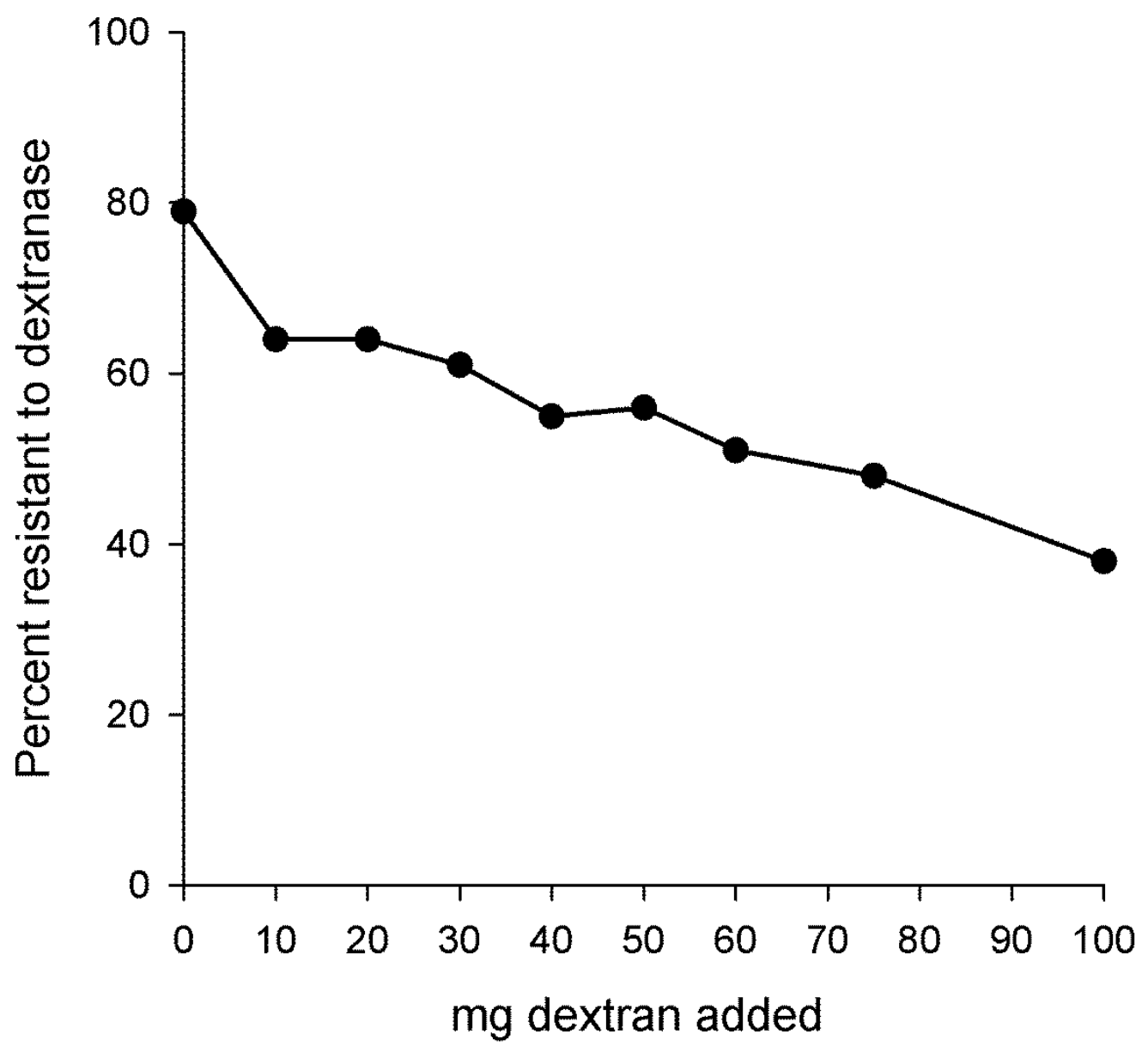

Figure 4.

4

40

41

42

43

44

45

46

47

48

49

50

51

52

53

54

55

56

57

58

59

60

61

62

63 


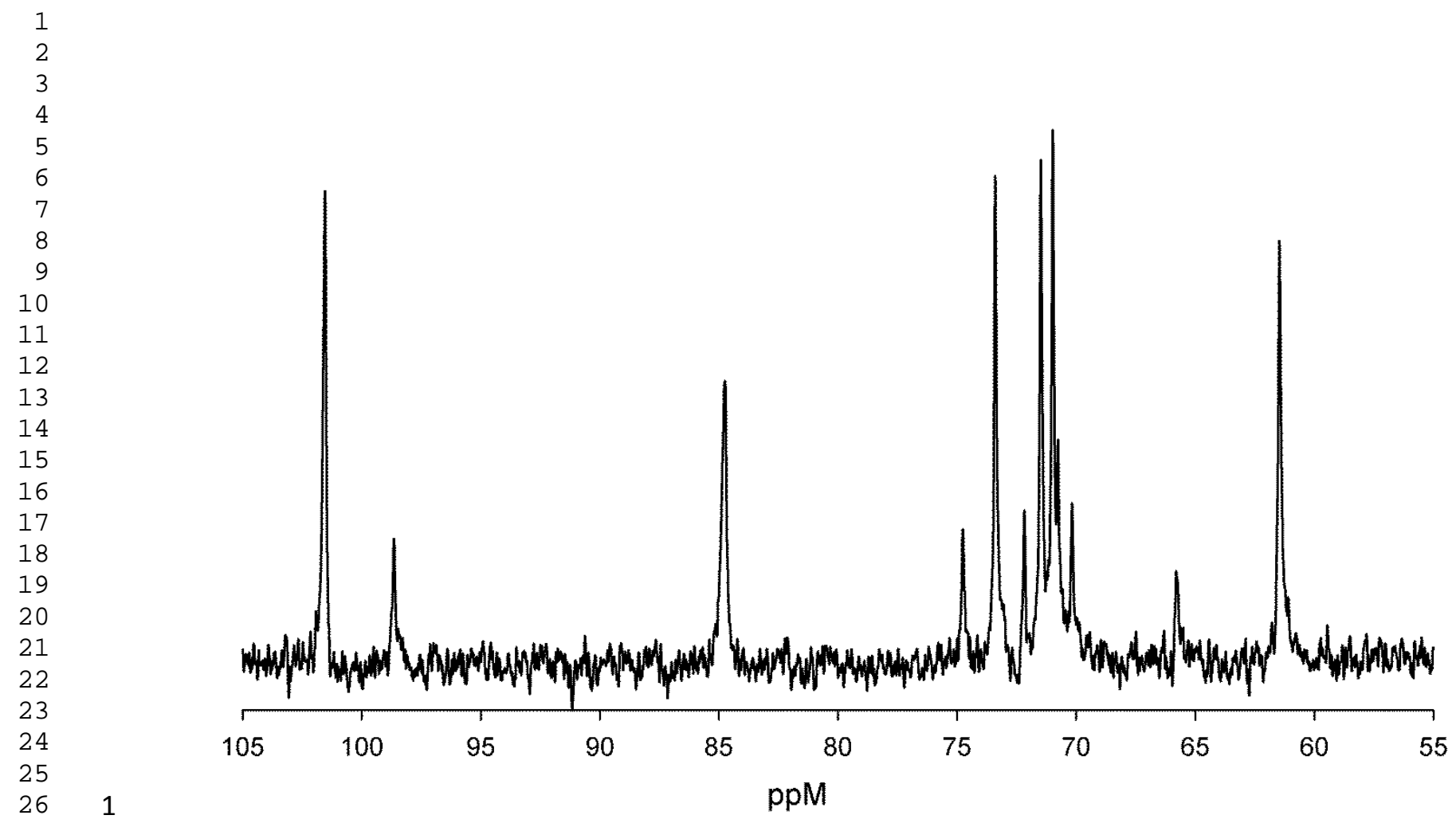



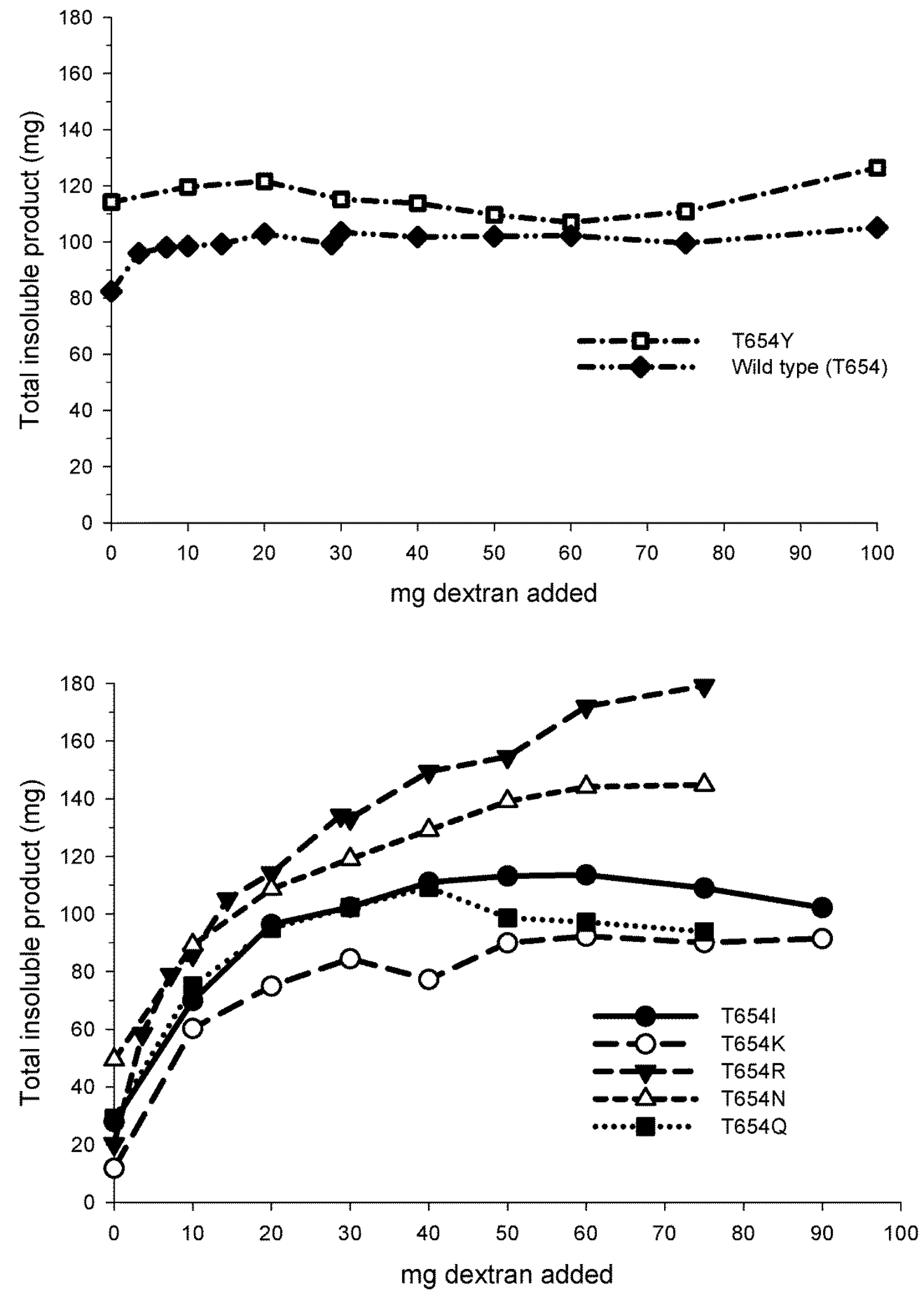

Figure 1. 


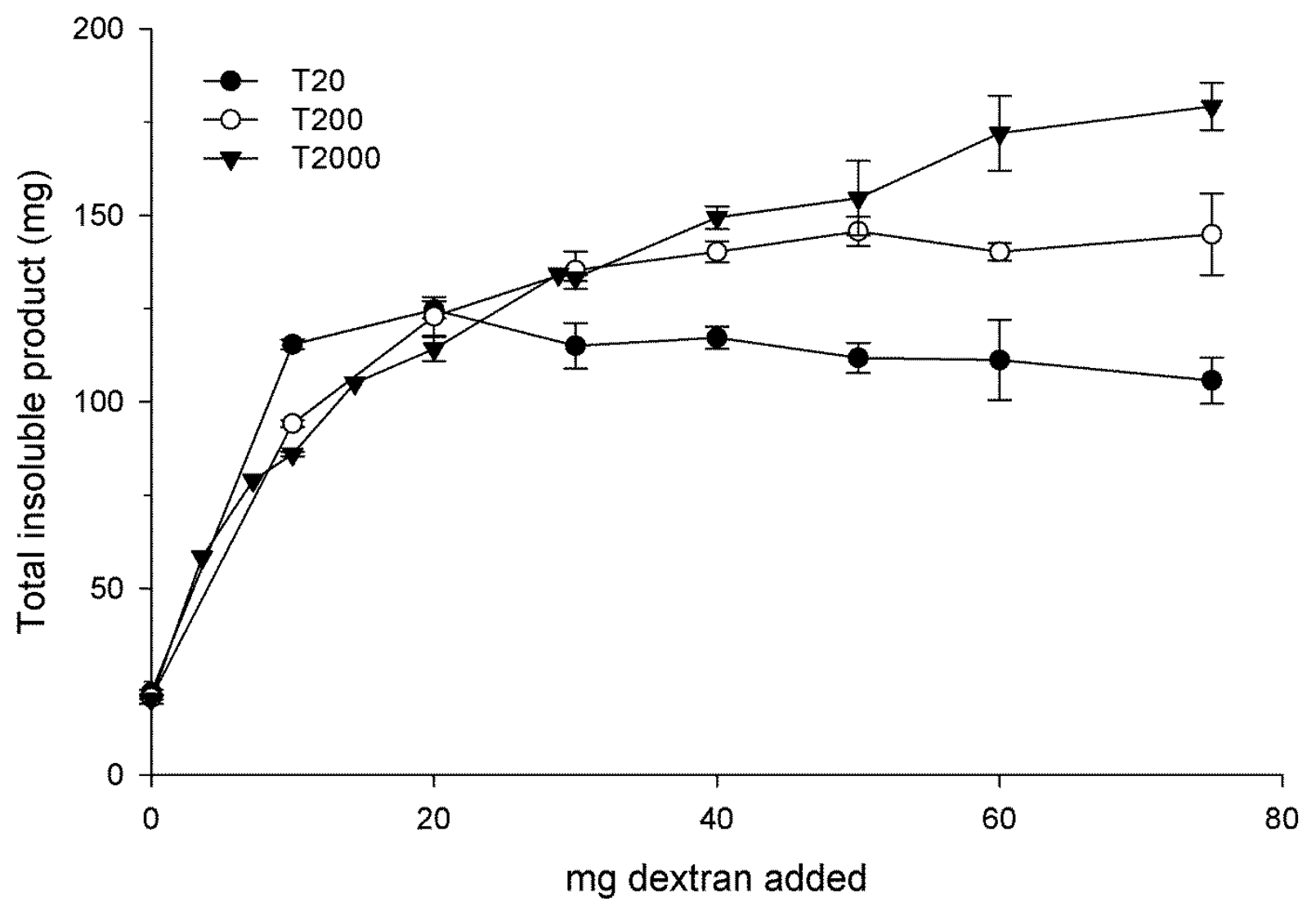

Figure 2. 


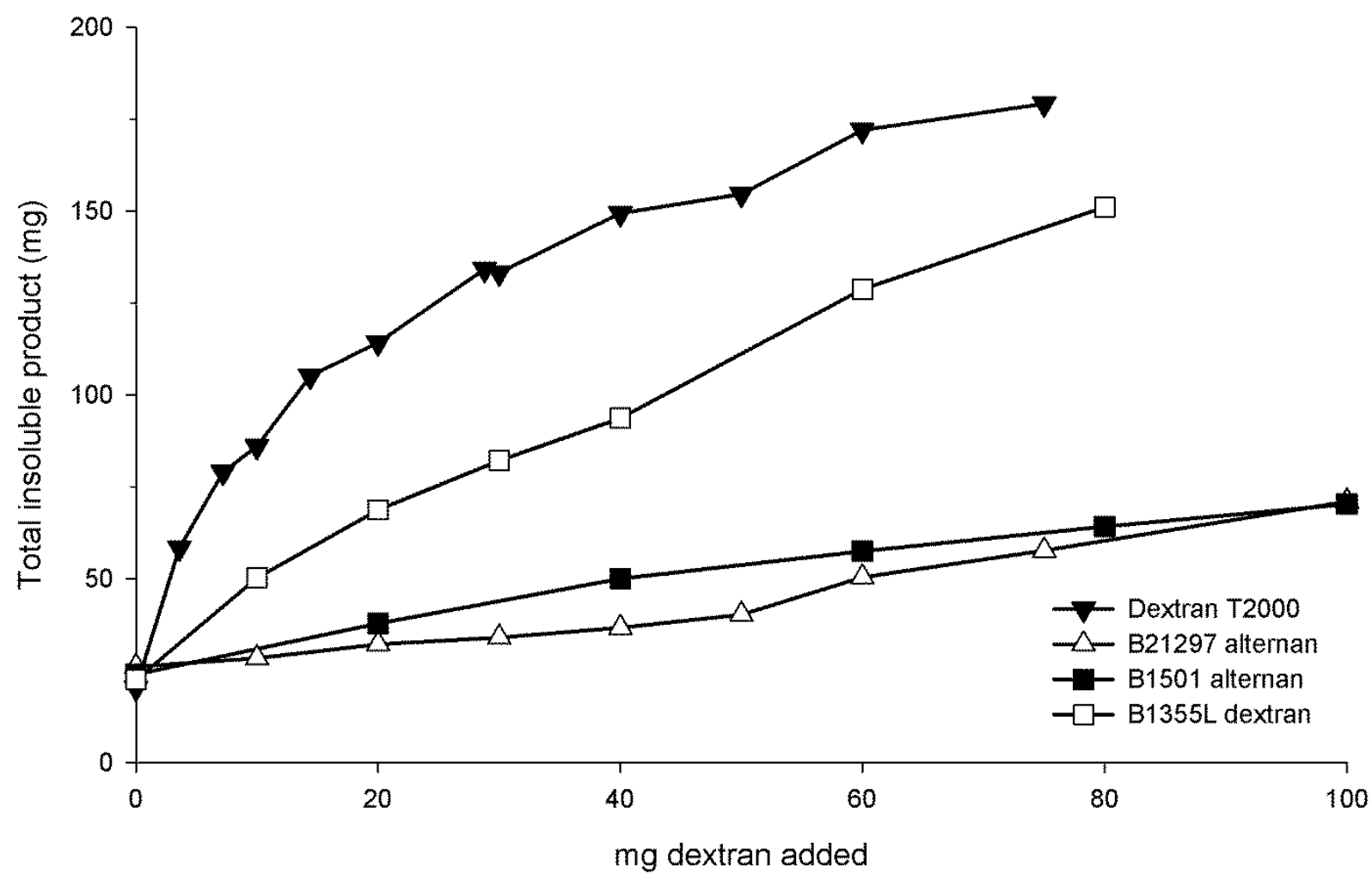

Figure 3. 


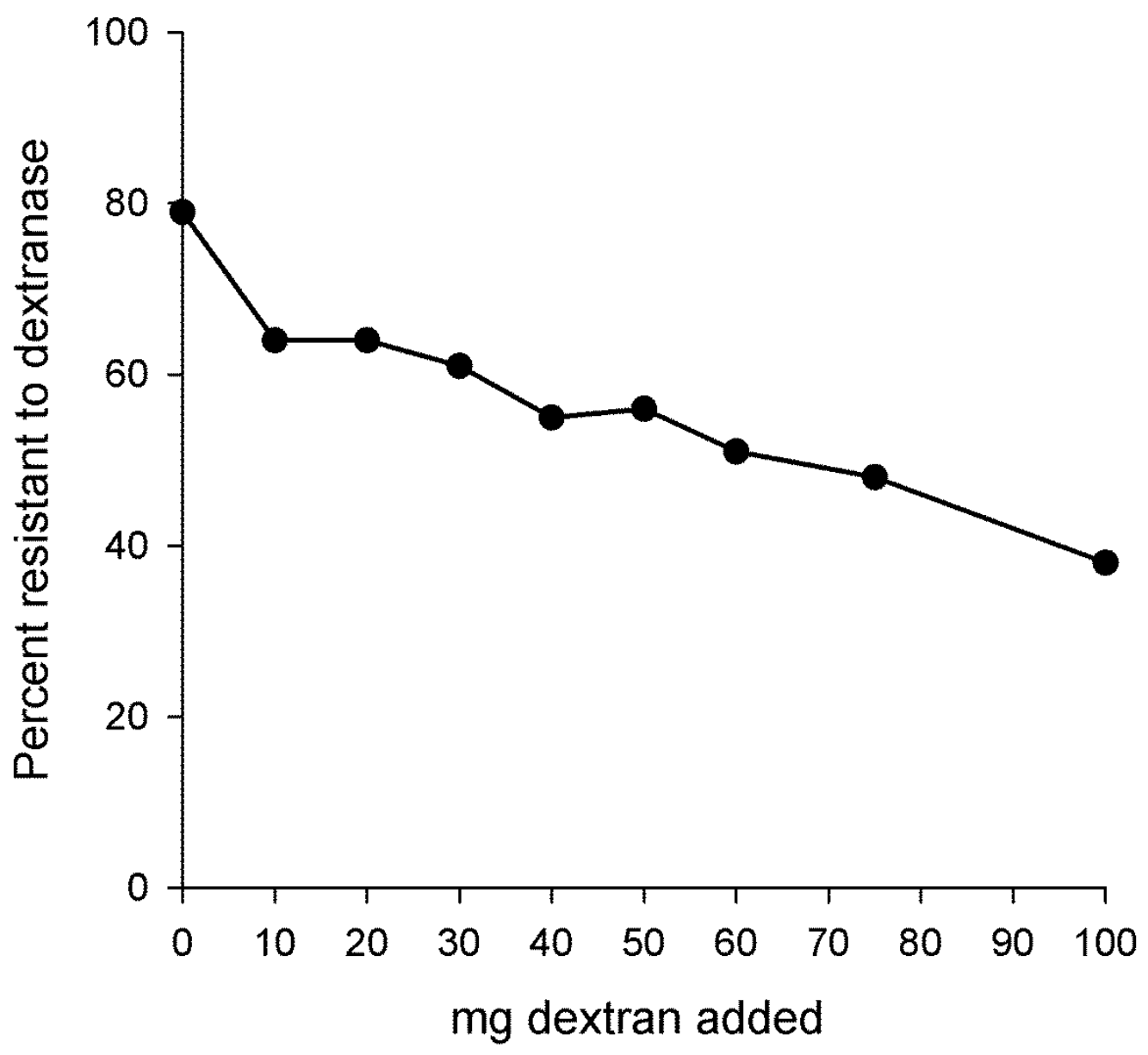

Figure 4. 


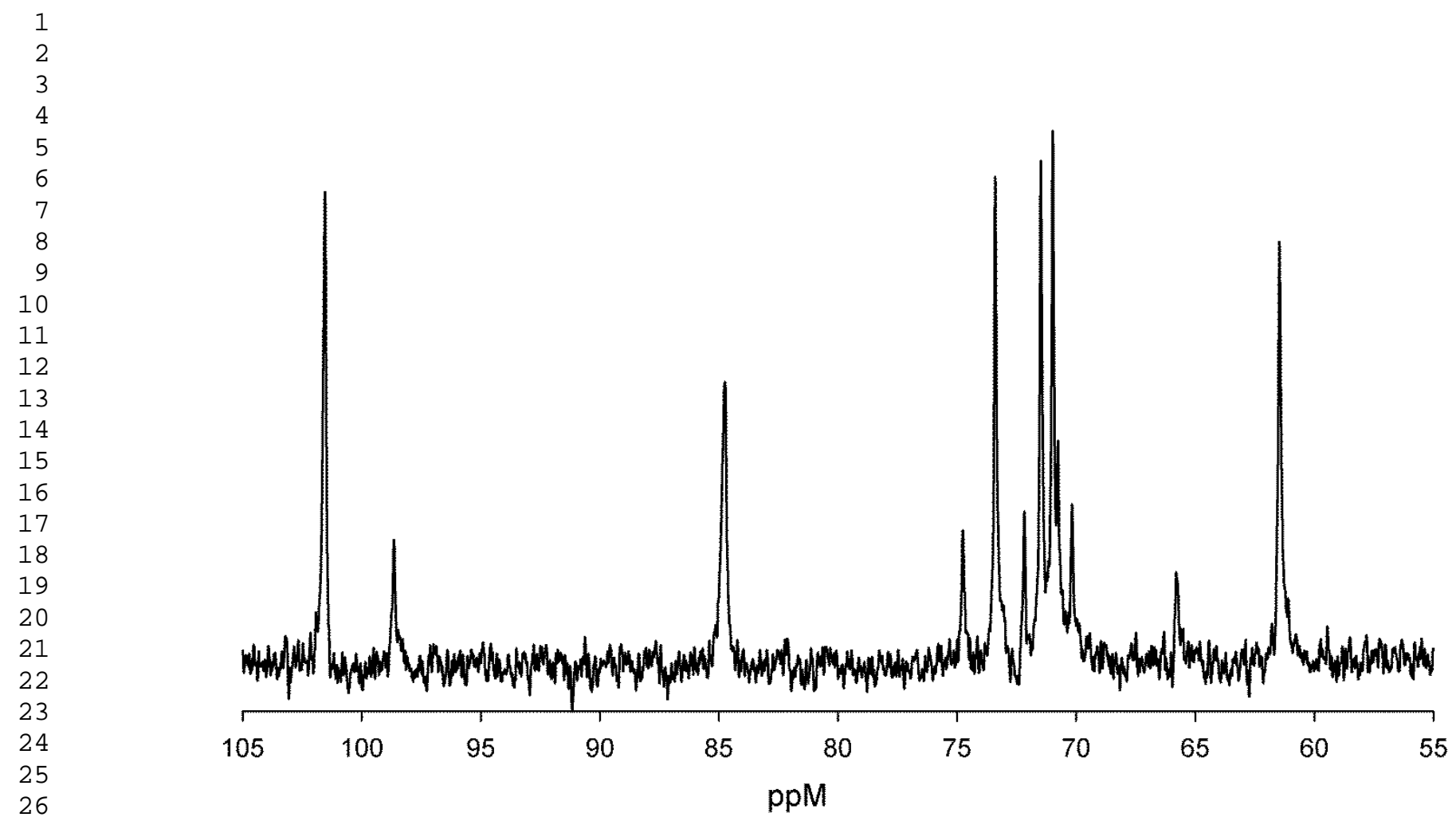




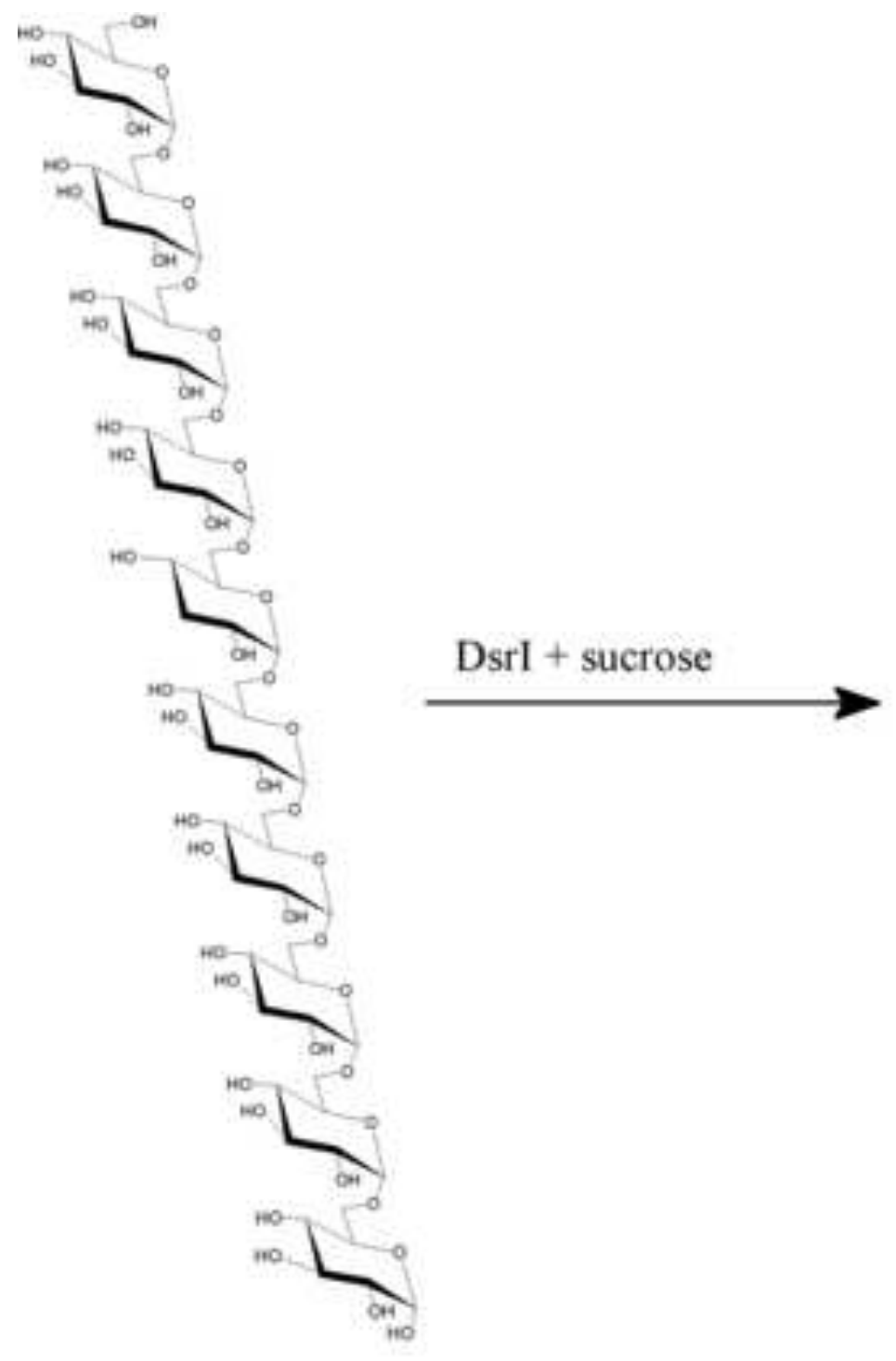

soluble dextran

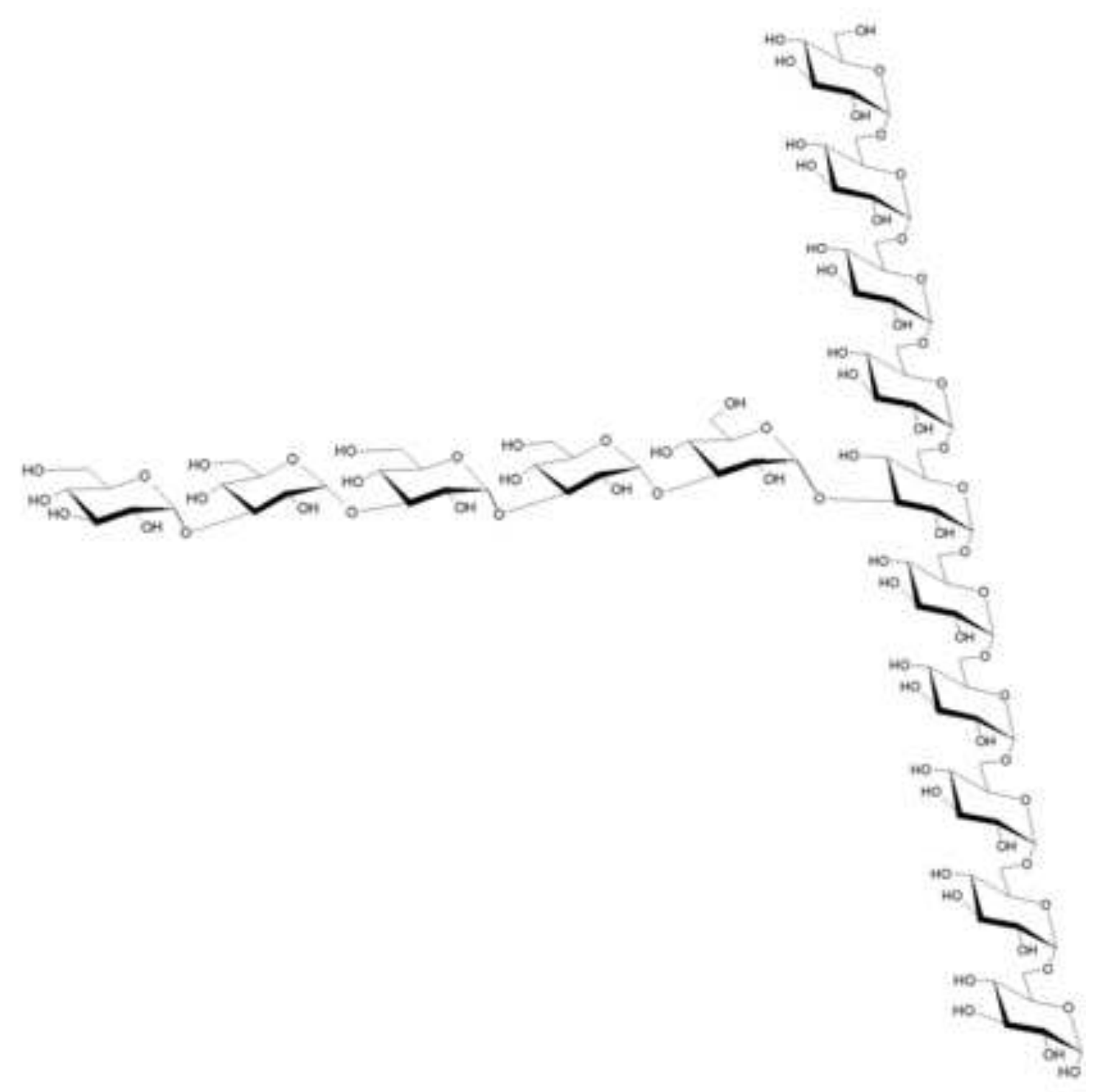

insoluble glucan

(activator and acceptor) 